\title{
Effect of types of stimuli, handedness and gender differences on reaction time among adults students during the COVID-19 pandemic
}

\author{
Dindar S. Bari ${ }^{1}$ Haval Y. Yacoob Aldosky ${ }^{2}$ \\ ${ }^{1}$ Department of Physics, Faculty of Science, University of Zakho, Zakho, Kurdistan region, Iraq; ${ }^{2}$ Department of Physics, \\ College of Science, University of Duhok, Duhok, Kurdistan region, Iraq
}

\begin{abstract}
Study aim: The COVID-19 pandemic has unhinged the lives of people across the globe, in particular, university students who are home-schooling. No study has investigated the influence of specific parameters on reaction time (RT) among university students during the COVID-19 pandemic. The current study aims to describe the relationship between RT and parameters (types of stimuli, handedness, and gender differences) that may affect its values during the COVID-19 pandemic.

Material and methods: RT of 60 volunteers to visual and auditory stimuli were recorded using the drop ruler method. RT was compared within-subject with respect to handedness and type of stimulus, and between subjects with regards to gender.

Results: Although a small difference between RT reported as a function of hands and gender was observed, these results were statistically insignificant. However, females had a significant shorter RT to visual than the auditory stimulus.

Conclusions: Findings showed that no significant differences were obtained between all comparisons made, except between females RT to visual stimulus and auditory stimulus. This can be attributed to the high level of stress and anxiety that may occur among students due to the COVID-19, which is the most prevalent and dangerous topic for university students, especially female students.
\end{abstract}

\section{Keywords: Reaction time - Visual stimulus - Auditory stimulus - Dominant hand - Non-dominant hand}

\section{Introduction}

Reaction time (RT) is the period between the presentation of a particular stimulus and the subsequent motor response of a person $[5,37]$. In addition, it can be considered as a behavioral measure to assess the capacity of the cognitive system to process information [5, 37]. Physiologically, RT is dependent on the speed of the sensorimotor cycle, which is consisted of the initial stimulus detection, the process of transfer of the information via the afferent nerves, response generation from the central nervous system, and the final response $[1,19,37]$. Therefore, the whole process is not only involving signal transmission but also neural processing throughout the various perceptual, motor, and cognitive areas in the brain [29].

Generally, there are three types of RT; simple RT, Recognition RT, and Choice RT [4]. The simple RT is the time between the presence of a stimulus and its detection by an observer [24]. Recognition RT is the response to a specific stimulus and stops once other types of stimuli appear. Choice RT involves the selection of a response for each type of stimulus [4]. Simple RT is the shortest of all, whereas choice RT is the longest of all [12].

$\mathrm{RT}$ is a relevant variable in many areas such as sports, academics, music, driving, and several other activities of human daily life $[33,38]$. The reacting abilities of a person due to these activities can be predicted through measuring the RT of the person [2]. Moreover, the processing speed of the central nervous system and the coordination between the sensory and motor systems can be evaluated by the measurement of RT. Furthermore, RT can be employed as an indirect index of the processing capability of the Central Nervous System [21].

RT to a stimulus is affected by various factors, some of them dependent on the own person such as age, gender, and handedness and some are related to the stimulus like intensity, duration, and also practice to the stimulus $[3,10$, $24,45]$. With regards to the internal factors, RT is influenced by cognitive processes such as attention $[9,30]$. 
Attention is the process of activation and selection, distribution, and maintenance of psychological activity [7, 20]. Moreover, according to Reigal et al. [37], both simple and complex RTs are influenced by weekly physical activity, in which those who did more hours of physical activity during a week showed less simple and complex RTs. Furthermore, RT could also be influenced by factors like stress and anxiety. It is reported that reduction in RT is associated with stressful situations [40, 44]. In addition, Singh et al. [40] showed that stress within a limit gives positive feedback to Central Nervous System information processing consequently raising the efficiency of individuals and decreasing their RT.

RT due to various stimuli is investigated in several studies. A few studies $[34,42]$ reported that RT to auditory stimulus is faster than visual or any other given stimulus. On the other hand, several studies [23, 39, 43, 46] showed the opposite results and confirm that RT to visual stimulus is faster than RT to the auditory stimulus. Concerning gender conflicting results are reported. In a study, Engel et al. [13], revealed that males tend to be faster than females in responding to the auditory stimulus. In another study, Dane et al. [8], showed the difference between male and female handball players with regards to eye-hand RT. Oppositely, Dey et al. [11] did not observe significant differences in RT in response to visual or auditory stimuli in either gender.

COVID-19 pandemic has generally caused various psychological problems among the public in general and students in special. Students encounter unique challenges causing poor mental health in the wake of the COVID-19 outbreak [47]. In addition, stress, anxiety, depression, etc. are observed during the COVID-19 pandemic among students [14-16, 31, 32, 35, 36, 41, 47].

As far as we know, few published studies directly explore whether the type of stimuli or dominant and nondominant hand affects RT in both genders. To date, age and gender differences parameters are presumed to be associated with RT, however, there has been no direct investigation of these and other parameters in abnormal conditions such as during the COVID-19 pandemic.

This study aims to find out differences in RT due to visual stimulus compared to the auditory stimulus and the dominant hand compared to the non-dominant hand of both genders via using the ruler drop method during the COVID-19 pandemic. It was hypothesized that the RT of the participants would be different due to visual and auditory stimuli and also due to the dominant and nondominant hands. Specifically, we expect that the RT of auditory stimulus would be faster than the visual one, that the RT would be faster in the dominant hand compared to the non-dominant hand. Based on the gender differences, it was also hypothesized that the RT for males would be faster than that for females.

\section{Material and methods}

A total of 60 (30 males and 30 females) students physically healthy without any hearing or visual disorder in the ages ranging from 20-23 years were recruited from the Physics Department, the University of Duhok who voluntarily underwent the experiment. In addition, all students gave written informed consent for participation in the study. Throughout the data collection process, the tenets established in the Helsinki Declaration were respected. All the measurements were conducted at the University of Duhok.

The participants were seated in a comfortable chair throughout the experiments in a sound-free room with good visibility conditions. The simple RT was measured by catching a vertical ruler that is suddenly released due to auditory and visual stimuli.

For recording the auditory RT, the participants were instructed to respond as soon as they heard the sound (drop). Moreover, the participants were first asked to wear an eye mask (cover), then catch the ruler by using the dominant hand as soon as they heard the auditory stimulus. For recording the visual RT, the participants were instructed to respond as soon as they saw the ruler being released by catching it. Two readings for each stimulus were taken and their respective averages calculated.

The distance (y) of the ruler was recorded in meter and using Newton's $2^{\text {nd }}$ law of motion, RT in seconds was calculated using the following formula,

$$
\mathrm{RT}=\sqrt{\frac{2 \mathrm{y}}{\mathrm{g}}} \text {, where } \mathrm{g} \text { is acceleration due to gravity. }
$$

The Statistical Package for Social Sciences (IBM SPSS Statistics 22) was conducted for data analysis. For within-subject analysis, the paired t-test was used and for between-subject analysis independent t-test was used. The differences in the RT were evaluated statistically in terms of gender differences, types of stimuli, and handedness.

In order to further assess differences in means RT for within-subject analysis, two-way repeated measures ANOVA was used. RT as the dependent variable, and gender (males and females), handedness (dominant and non-dominant hands), and stimuli (visual and auditory) as independent variables.

\section{Results}

\section{Mean RT to visual stimulus for male $(n=30)$ and female $(n=30)$ as a function of dominant and non-dominant hands}

RT data of male to visual stimulus are given in Table 1. It is clear through the mean RT that, the male RT to visual 
stimulus for the dominant hand is shorter than the nondominant hand. However, these findings were statistically insignificant $(p>0.05)$

Table 1 also contains the data of RT for females to visual stimulus. It can be seen through the Table that, female RT unlike male RT to visual stimulus for non-dominant hand is faster than dominant hand, but these results were statistically insignificant as $(p>0.05)$.

\section{Mean RT to auditory stimulus for male $(n=30)$ female $(n=30)$ as a function of dominant and non-dominant hands}

The results reported in Table 2 reveal that males with non-dominant hands can respond slightly faster to auditory stimulus than with dominant hands. However, the difference was statistically insignificant $(p>0.05)$.

Also, Table 2 displays the mean RT and statistical analysis of females responding to auditory stimulus for dominant and non-dominant hands. It appears through the data that RT of female to the auditory stimulus with dominant hand is faster than non-dominant hand oppositely to male.

Mean RT for male $(n=30)$ and female $(n=30)$ using the dominant hand as a function of the type of stimuli

Table 3 presents RT to auditory and visual stimuli for males using the dominant hand. It can be seen that males can respond faster to visual than to auditory stimuli. However, the difference was statistically insignificant as indicated by paired t-Test.

Also, Table 3 presents female RT to both auditory and visual stimuli using the dominant hand. It is clear that female RT to visual stimulus is faster than auditory stimulus, but statistically insignificantly $(p>0.05)$.

\section{Mean RT for male $(n=30)$ and female $(n=30)$ using the non-dominant hand as a function of the type of stimuli}

Table 4 shows RT for males (non-dominant hand) in responding to visual and auditory stimuli. From the data

Table 1. Mean RT to visual stimulus for male and female as a function of Handedness (dominant and non-dominant hands)

\begin{tabular}{|c|c|c|c|c|}
\hline \multirow{2}{*}{ Gender/Handedness } & \multirow{2}{*}{ Mean $\mathrm{RT} \pm \mathrm{SD}[\mathrm{msec}]$} & \multicolumn{2}{|c|}{ 95\% Confidence Interval } & \multirow{2}{*}{$p$-value } \\
\hline & & from & to & \\
\hline Male/Dominant & $196.83 \pm 25.93$ & \multirow{2}{*}{-15.28} & \multirow{2}{*}{4.76} & \multirow{2}{*}{0.292} \\
\hline Male/Non-dominant & $202.09 \pm 17.63$ & & & \\
\hline Female/Dominant & $198.36 \pm 24.28$ & \multirow{2}{*}{-8.98} & \multirow{2}{*}{16.77} & \multirow{2}{*}{0.541} \\
\hline Female/Non-dominant & $194.46 \pm 32.61$ & & & \\
\hline
\end{tabular}

Table 2. Mean RT to Auditory stimulus for male and female as a function of Handedness (dominant and non-dominant hands)

\begin{tabular}{lccc}
\hline \multirow{2}{*}{ Gender/Handedness } & Mean RT \pm SD [msec] & \multicolumn{2}{c}{$95 \%$ Confidence Interval } \\
Male/Dominant & $203.85 \pm 21.23$ & from & to \\
Male/Non-dominant & $201.25 \pm 28.10$ & -11.74 & 16.94 \\
Female/Dominant & $199.28 \pm 31.43$ & & 0.714 \\
Female/Non-dominant & $208.58 \pm 24.78$ & -21.44 & 2.83 \\
\hline
\end{tabular}

Table 3. Mean RT for male and female (dominant hand) as a function of stimuli

\begin{tabular}{|c|c|c|c|c|}
\hline \multirow{2}{*}{ Gender/Stimuli } & \multirow{2}{*}{ Mean $\mathrm{RT} \pm \mathrm{SD}[\mathrm{msec}]$} & \multicolumn{2}{|c|}{ 95\% Confidence Interval } & \multirow{2}{*}{$p$-value } \\
\hline & & from & to & \\
\hline Male/Visual & $196.83 \pm 25.93$ & \multirow{2}{*}{-19.14} & \multirow{2}{*}{5.10} & \multirow{2}{*}{0.246} \\
\hline Male/Auditory & $203.85 \pm 21.23$ & & & \\
\hline Female/Visual & $198.36 \pm 24.28$ & \multirow{2}{*}{-16.14} & \multirow{2}{*}{14.30} & \multirow{2}{*}{0.903} \\
\hline Female/Auditory & $199.28 \pm 31.43$ & & & \\
\hline
\end{tabular}


Table 4. Mean RT for male and female (non-dominant hand) as a function of stimuli

\begin{tabular}{lccc}
\hline Gender/ Stimuli & Mean RT \pm SD $[\mathrm{msec}]$ & 95\% Confidence Interval & from \\
\cline { 3 - 4 } & & to & \multirow{2}{*}{0.898} \\
Male/ Visual & $202.09 \pm 17.63$ & -12.38 & 14.05 \\
Male/ Auditory & $201.25 \pm 28.10$ & & 0.028 \\
Female/ Visual & $194.46 \pm 32.61$ & -26.60 & -1.64 \\
Female/ Auditory & $208.58 \pm 24.78$ & & \\
\hline
\end{tabular}

shown in Table 4, it appears that male RT to the auditory stimulus was lower (oppositely to results once using their dominant hands) than visual stimulus.

Females, on the other hand, again are faster in responding to visual stimuli than auditory stimulus once using their non-dominant hands. These findings were statistically significant $(p<0.05)$.

Mean RT to visual stimulus for male $(n=30)$ and female $(n=30)$ for dominant and non-dominant hands as a function of gender

Table 5 shows the RT responses of both males and females to visual stimulus using the dominant hand. It is clear that male is faster than female for responding to visual stimulus as indicated by mean RT value, although these findings are statistically insignificant $(p>0.05)$.

Also based on the results shown in Table 5, once using non-dominant females were able to respond faster to visual stimulus than males. However, again the results are non-significant statistically.

\section{Mean RT to auditory stimulus for male $(n=30)$ and female $(n=30)$ for dominant hand as a function of gender}

According to the data reported in Table 6 female RT is shorter than male RT to auditory stimulus once employing the dominant hand. However female RT is longer than male RT when utilizing the non-dominant. Once these results were analyzed statistically, all the differences were insignificant as $(p>0.05)$.

\section{Analysis with two repeated factors ANOVA}

The actual result of the two-way ANOVA - that is, whether any of the two independent variables or their interaction are statistically significant for within-subjects analysis. None of the independent variables (handedness, stimuli, and gender) were statistically significant (see Table 7). However, the interaction effects of all of them had a marked effect on the RT values although they were statistically insignificant. This means that the effect of one independent variable does not depend on the effect of the

Table 5. Mean RT to visual stimulus for dominant and non-dominant hands as a function of gender

\begin{tabular}{|c|c|c|c|c|}
\hline \multirow{2}{*}{ Handedness/Gender } & \multirow{2}{*}{ Mean $\mathrm{RT} \pm \mathrm{SD}[\mathrm{msec}]$} & \multicolumn{2}{|c|}{ 95\% Confidence Interval } & \multirow{2}{*}{$p$-value } \\
\hline & & from & to & \\
\hline Dominant/Male & $196.83 \pm 25.93$ & -14.512 & 11.457 & \multirow{2}{*}{0.815} \\
\hline Dominant/Female & $198.36 \pm 24.28$ & -14.514 & 11.458 & \\
\hline Non-dominant/Male & $202.09 \pm 17.63$ & -5.92 & 21.17 & \multirow{2}{*}{0.264} \\
\hline Non-dominant/Female & $194.46 \pm 32.61$ & -6.00 & 21.26 & \\
\hline
\end{tabular}

Table 6. Mean RT to auditory stimulus for dominant and non-dominant hands as a function of gender

\begin{tabular}{|c|c|c|c|c|}
\hline \multirow{2}{*}{ Handedness/Gender } & \multirow{2}{*}{ Mean $\mathrm{RT} \pm \mathrm{SD}[\mathrm{msec}]$} & \multicolumn{2}{|c|}{ 95\% Confidence Interval } & \multirow{2}{*}{$p$-value } \\
\hline & & from & to & \\
\hline Dominant/Male & $203.85 \pm 21.23$ & -9.29 & 18.43 & \multirow{2}{*}{0.512} \\
\hline Dominant/Female & $199.28 \pm 31.43$ & -9.33 & 18.47 & \\
\hline Non-dominant/Male & $201.25 \pm 28.10$ & -21.02 & 6.35 & \multirow{2}{*}{0.288} \\
\hline Non-dominant/Female & $208.58 \pm 24.78$ & -21.03 & 6.36 & \\
\hline
\end{tabular}


Table 7. Two repeated factors ANOVA analysis

\begin{tabular}{lccc}
\hline Source & Mean Square & Sig. & Partial Eta Squared \\
\hline Stimuli & 41.792 & 0.794 & 0.001 \\
Stimuli $\times$ Gender & 294.529 & 0.490 & 0.008 \\
Handedness & 244.360 & 0.515 & 0.007 \\
Handedness $\times$ Gender & 107.294 & 0.666 & 0.003 \\
Stimuli $\times$ Handedness & 28.380 & 0.820 & 0.001 \\
Stimuli $\times$ Handedness $\times$ Gender & 1663.582 & 0.085 & 0.050 \\
\hline
\end{tabular}

other independent variable (there is no interaction effect). It should be noted that the main effect of the independent variables (stimuli and non-dominant hand) is significant only in females as shown in Table 4.

\section{Discussion}

Studies on RT are continuing. Many researchers and scientists are continuously coming up with different ways of explaining the disparities observed in researches. In this study, comparisons were made between; the RT variability of the participants as a function of handedness, the RT variability of the individuals in terms of stimuli, and finally the RT variability of the participants with regards to gender differences.

The effect of handedness on RT within-subject was an interesting question. The results (Table 1 and Table 2) reveal that the RT was not significantly $(p>0.05)$ handedness dependent for both genders and both stimuli. The relationship between handedness and RT does not differ substantially between genders. However, handedness appears to exert a greater influence on females' than does on males' RT, especially for the non-dominant hand. These findings are in line with the results reported by Brown et al. [6].

In general, measuring of mean RT on the basis of stimuli showed that both males and females are faster in responding to visual stimulus than auditory stimulus in agreement with $[17,18]$. In addition, females had a significantly shorter RT for visual stimulus than the auditory stimulus for non-dominant hand $(p<0.05)$ as indicated in Table 4. However, for the dominant hand, no significant $(p>0.05)$ differences were observed for both genders.

Overall, there were no statistically significant gender differences between the mean RT of subjects. These results are consistent with the findings of more recently published reports, which show that there are no differences in the RT between genders $[11,27,28,45]$. This may represent the influence of factors such as the increasing trend of exercise and training among female students, as it is associated with faster RT [23]. RT in females is also subject to timing with respect to the menstruation cycle [22]. Furthermore, RT values could also be influenced by an increase in the stress and anxiety levels among students, in particular, females $[40,44]$ as a result of the spread COVID-19 pandemic, which might lead to a lack of statistical insignificance. However, gender differences were found in other studies $[23,25]$. The reason for these inconsistent findings could be related to the different mean ages in these studies [26], and also such studies are done in normal conditions other than abnormal conditions like the spread of COVID-19.

Males were faster than females when testing visual stimulus for the dominant hand (Table 5). Whereas, for the non-dominant hand, the results were opposite and females were faster. There was, however, no statistically significant difference in mean RT when gender comparison was made for both hands. For auditory stimulus (Table 6), the reverse was observed. This observation suggests that in terms of having fast RT being non-dominant and female confers certain inherent advantages [6].

The impact of interaction effects for all variables on RT within subjects was also investigated. Although a noticeable value of Partial Eta Squared (5\%) is obtained, the insignificant association $(p<0.085)$ between interaction terms (handedness, stimuli, and gender) showed that the effect of any of these independent variables does not depend on the level of the other independent variable.

Finally, the claim of the current study can be further substantiated by comparing the percentage difference of RT values of this study with earlier researches done by $[23,25]$. The results show that our RT values are considerably less than the RT reported in these studies. For instance, the percentage difference of visual stimulus for males and females was about $48.06 \%$., $55.47 \%$ respectively.

\section{Limitations of this study}

The inconsistency of some of the results with previous studies may be due to abnormal conditions such as the spread of COVID-19, so, likely, the results of this study may not be generalized to other normal conditions. Another limitation may be that this study was conducted using a simple RT. Choice RT can be used for future studies. 


\section{Conclusion}

We conclude that females had a significantly shorter RT for visual stimulus than auditory stimulus once using their non-dominant hand. Our data support the hypothesis, which stated that there are no differences in the RT between genders. Furthermore, no statistically significant differences in mean RT were observed when comparison was made in terms of handedness. The lack of statistical significance obtained in the analysis may be attributed to the increased level of stress and anxiety in college students due to the abnormal conditions of the COVID-19 pandemic, which is the most prevalent and serious issue for students, especially females.

Conflict of interest: Authors state no conflict of interest.

\section{References}

1. Adleman N.E., Chen G., Reynolds R.C., Frackman A., Razdan V., Weissman D.H., Pine D.S., Leibenluft E. (2016) Age-related differences in the neural correlates of trial-to-trial variations of reaction time. Dev. Cogn. Neurosci., 19: 248-257.

2. Aranha V.P., Joshi R., Samuel A.J., Sharma K. (2015) Catch the moving ruler and estimate reaction time in children. Indian J. Med. Health Sci., 2: 23-26.

3. Baayen R.H., Milin P. (2010) Analyzing reaction times. Int. J. Psychol. Res., 3: 12-28.

4. Boisgontier M.P., Wittenberg G.F., Fujiyama H., Levin O., Swinnen S.P. (2014) Complexity of central processing in simple and choice multilimb reaction-time tasks. PloS one, 9: e90457.

5. Bolfer C., Casella E.B., Baldo M.V.C., Mota A.M., Tsunemi M.H., Pacheco S.P., Reed U.C. (2010) Reaction time assessment in children with ADHD. Arq. NeuroPsiquiatr., 68: 282-286.

6. Brown A.A., Derkyi-Kwarteng L., Ackom C.K., Addae E., Newton F., Amoah D., Blemano D.N. (2017) Simple reaction time: how it relates to body mass index (BMI), gender and handedness in Ghanaian students. $J$. Med. Sci., 49: 1-7.

7. Chun M.M., Golomb J.D., Turk-Browne N.B. (2011) Turk-Browne, A taxonomy of external and internal attention. Ann. Rev. Psychol., 62: 73-101.

8. Dane S., Erzurumluoglu A.L.I. (2003) Erzurumluoglu, Sex and handedness differences in eye-hand visual reaction times in handball players. Int. J. Neurosci., 113: 923-929.

9. Deary I.J., Der G., (2005) Reaction time, age, and cognitive ability: longitudinal findings from age 16 to
63 years in representative population samples. Aging Neuropsychol. Cogn., 12: 187-215.

10. Der G., Deary I.J. (2006) Age and sex differences in reaction time in adulthood: results from the United Kingdom Health and Lifestyle Survey. Psychol. Aging, 21: 62-73.

11. Dey C.K., Daokar R.G. (2018) A gender-based comparative study of visual and auditory reaction time on 1st year medical students "before" and "after" caffeine intake. Int. J. Sci. Study, 6: 39-42.

12. Donders F.C. (1969) On the speed of mental processes. Acta Psychol., 30: 412-431.

13. Engel B.T., Thorne P.R., Quilter R.E. (1972) On the relationships among sex, age, response mode, cardiac cycle phase, breathing cycle phase, and simple reaction time. J. Gerontol., 27: 456-460.

14. Faisal R.A., Jobe M.C., Ahmed O., Sharker T. (2021) Mental health status, anxiety, and depression levels of Bangladeshi university students during the COVID-19 pandemic. Int. J. Ment. Health Addict., 1-16.

15. Fruehwirth J.C., Biswas S., Perreira K.M. (2021) The Covid-19 pandemic and mental health of first-year college students: Examining the effect of Covid-19 stressors using longitudinal data. PloS one, 16: e0247999

16. Gavin B., Lyne L., McNicholas F. (2020) Mental health and the COVID-19 pandemic. Ir. J. Psychol. Med., 37: 156-158.

17. Goldstone S., Lhamon W.T. (1974) Studies of auditoryvisual differences in human time judgment: 1. Sounds are judged longer than lights. Percept. Mot. Skills, 39: 63-82.

18. Green D.M., Von Gierke S.M. (1984) Visual and auditory choice reaction times. Acta Psychol., 55(3): p. 231-247.

19. Greenhouse I., King M., Noah S., Maddock R.J., Ivry R.B. (2017) Individual differences in resting corticospinal excitability are correlated with reaction time and GABA content in motor cortex. J. Neurosci., 37: 2686-2696.

20. Greimel E., Wanderer S., Rothenberger A., HerpertzDahlmann B., Konrad K., Roessner V. (2011) Attentional performance in children and adolescents with tic disorder and co-occurring attention-deficit/hyperactivity disorder: new insights from a $2 \times 2$ factorial design study. $J$. $A b$ norm. Child Psychol., 39: 819-828.

21. Ilamkar K.R. (2014) Analysis of human information processing in performance and cognition. Int. J. Res. Health Sci., 2: 36-40.

22. Jadhav S.S. (2019) Evaluation of visual reaction time during pre-and post-menstrual phase. Natl. J. Physiol. Pharm. Pharmacol., 9: 398-400.

23. Jain A., Bansal R., Kumar A., Singh K.D. (2015) A comparative study of visual and auditory reaction times on the basis of gender and physical activity levels of medical first year students. Int. J. Appl. Basic Med. Res., 5: 124-127. 
24. Jayaswal A. (2016) Comparison between auditory and visual simple reaction times and its relationship with gender in 1st year MBBS students of Jawaharlal Nehru Medical College, Bhagalpur, Bihar. Int. J. Med. Res. Rev., 4: 1228-1232.

25. Jose S., Gideon Praveen K. (2010) Comparison between auditory and visual simple reaction times. Neurosci. Med., 1: 30-32.

26. Kalb R., Jansen S., Reulbach U., Kalb S. (2004) Sex differences in simple reaction tasks. Percept. Mot. Skills, 98: 793-802.

27. Kamath A., Shastry R. (2021) Diurnal Variation in Visual Simple Reaction Time between and within Genders in Young Adults: An Exploratory, Comparative, Pilot Study. Sci. World J., 9: 1-5.

28. Kasozi K.I., Mbiydzneyuy N.E., Namubiru S., Safiriyu A.A., Sulaiman S.O., Okpanachi A.O., Ninsiima H.I. (2018) A study on visual, audio and tactile reaction time among medical students at Kampala International University in Uganda. Afr. Health Sci., 18: 828-836.

29. Kuang S. (2017) Is reaction time an index of white matter connectivity during training? Cogn. Neurosci., 8: 126-128.

30. Leckie R.L., Oberlin L.E., Voss M.W., Prakash R.S., Szabo-Reed A., Chaddock-Heyman L., Phillips S.M., Gothe N.P., Mailey E., Vieira-Potter V.J., Martin S.A. (2014) BDNF mediates improvements in executive function following a 1-year exercise intervention. Front. Hum. Neurosci., 8: 1-12.

31. Liang L., Ren H., Cao R., Hu Y., Qin Z., Li C., Mei S. (2020) The effect of COVID-19 on youth mental health. Psychiatr. Q., 91: 841-852.

32. Meda N., Pardini S., Slongo I., Bodini L., Zordan M.A., Rigobello P., Visioli F., Novara C. (2021) Students' mental health problems before, during, and after COVID-19 lockdown in Italy. J. Psychiatr. Res., 134: 69-77.

33. Metin B., Wiersema J.R., Verguts T., Gasthuys R., van Der Meere J.J., Roeyers H., Sonuga-Barke E. (2016) Event rate and reaction time performance in ADHD: testing predictions from the state regulation deficit hypothesis using an ex-Gaussian model. Child Neuropsychol., 22: 99-109.

34. Pain M.T., Hibbs A. (2007) Sprint starts and the minimum auditory reaction time. J. Sports Sci., 25: 79-86.

35. Rakhmanov O., Dane S. (2020) Knowledge and anxiety levels of African university students against COVID-19 during the pandemic outbreak by an online survey. J. Res. Med. Dent. Sci., 8: 53-56.

36. Rakhmanov O., Demir A., Dane S. (2020) A brief communication: anxiety and depression levels in the staff of a Nigerian private university during COVID 19 pandemic outbreak. J. Res. Med. Dent. Sci., 8: 118-122.

37. Reigal R.E., Barrero S., Martín I., Morales-Sánchez V., Juárez-Ruiz de Mier R., Hernández-Mendo A. (2019) Relationships between reaction time, selective attention, physical activity, and physical fitness in children. Front. Psychol., 10: 1-8.

38. Sant'Ana J., Franchini E., da Silva V., Diefenthaeler F. (2017) Effect of fatigue on reaction time, response time, performance time, and kick impact in taekwondo roundhouse kick. Sports Biomech., 16: 201-209.

39. Shenvi D., Padma B. (1994) A comparative study of visual and auditory reaction times in males and females. Indian J. Physiol. Pharmacol., 38: 229-229.

40. Singh I., Singh Y., Vikramaditya B., Singh S. (2020) Impact of examination stress on response time in first-year medical students. Indian J. Basic Appl. Med. Res., 5: 733-739.

41. Son C., Hegde S., Smith A., Wang X., Sasangohar F. (2020) Effects of COVID-19 on college students' mental health in the United States: Interview survey study. J. Med. Internet Res., 22: e21279.

42. Thompson P.D., Colebatch J.G., Brown P., Rothwell J.C., Day B.L., Obeso J.A., Marsden C.D. (1992) Voluntary stimulus-sensitive jerks and jumps mimicking myoclonus or pathological startle syndromes. Mov. Disord., 7: 257-262.

43. Verleger R. (1997) On the utility of P3 latency as an index of mental chronometry. Psychophysiol., 34: 131-156.

44. Wawrzyniak A.J., Hamer M., Steptoe A., Endrighi R. (2016) Decreased reaction time variability is associated with greater cardiovascular responses to acute stress. Psychophysiol., 53: 739-748.

45. Woods D.L., Wyma J.M., Yund E.W., Herron T.J., Reed B. (2015) Factors influencing the latency of simple reaction time. Front. Hum. Neurosci., 9: 1-12.

46. Yagi Y., Coburn K.L., Estes K.M., Arruda J.E. (1999) Effects of aerobic exercise and gender on visual and auditory P300, reaction time, and accuracy. Eur. J. Appl. Physiol. Occup. Physiol., 80: 402-408.

47. Zhai Y., Du X. (2020) Addressing collegiate mental health amid COVID-19 pandemic. Psychiatry Res., 288: 113003.

\section{Received 04.08.2021 \\ Accepted 25.10.2021}

(C) University of Physical Education, Warsaw, Poland 